\title{
Reflexões sobre o papel da alimentação saudável no contexto
}

\author{
escolar
}

\section{Reflections on the role of healthy eating in the school contexto}

\author{
Cleiton Edmundo Baumgratz e-mail (Cleitonbiobaumgratz@ gmail.com) \\ Universidade Federal da Fronteira Sul (UFFS), Cerro Largo, RS \\ Riceli Gomes Czekalski e-mail (ricelicgbio@gmail.com) \\ Universidade Federal da Fronteira Sul (UFFS), Cerro Largo, RS \\ Mateus dos Santos Oliveira e-mail (matdioli96@gmail.com) \\ Universidade Federal da Fronteira Sul (UFFS), Cerro Largo, RS \\ Erica do Espirito Santo Hermel e-mail (eeshermel@ gmail.com) \\ Universidade Federal da Fronteira Sul (UFFS), Cerro Largo, RS
}

\begin{abstract}
Resumo: O presente texto apresenta um relato de experiência que aborda os princípios de uma alimentação saudável, na qual a atividade foi desenvolvida pelos bolsistas do programa PETCiências. O objetivo dessa ação era avaliar os conhecimentos prévios e subsequentes dos alunos a respeito do tema alimentação saudável, antes de ser introduzido o conteúdo pela professora da turma. A prática foi desenvolvida com a turma de $8^{\circ}$ ano do Ensino Fundamental de uma escola pública Estadual de Ensino Fundamental do município de Cerro Largo - RS. Tendo duração de uma hora aula, os dados foram obtidos a partir dos registros, anotações, questionários, discussões e confecção de cartaz após a finalização do encontro. Assim, identifica-se que além de promover a educação problematizadora e integradora dos discentes e consequentemente do ambiente escolar em que estão inseridos, a abordagem da alimentação saudável, permite a construção do conhecimento no componente curricular de Ciências fortalecendo e desenvolvendo a própria prática com a possibilidade de reflexão e conscientização.
\end{abstract}

Palavras-chave: Ensino de Ciências. Prática pedagógica. Currículo.

\begin{abstract}
This paper presents an experience report that addresses the principles of healthy eating, in which the activity was developed by the fellows of the PETCiencia program. The purpose of this action was to evaluate the students' previous and subsequent knowledge about the healthy eating theme, before the content was introduced by the class teacher. The practice was developed with the 8th grade elementary school of a state public elementary school in Cerro Largo - RS. Lasting one hour class, the data were obtained from the records, notes, questionnaires, discussions and poster making after the end of the meeting. Thus, it is identified that besides promoting the problematizing and integrating education of students and consequently the school environment in which they are inserted, the approach to healthy eating, allows the construction of knowledge in the curriculum component of Sciences strengthening and developing their own practice with possibility of reflection and awareness.
\end{abstract}


Keywords: Science Teaching. Pedagogical practice. Curriculum.

\section{INTRODUÇÃO}

O presente relato de experiência visa apresentar os resultados de uma atividade prática, realizada com o $8^{\circ}$ ano do Ensino Fundamental de uma escola da rede pública estadual do município de Cerro Largo - RS. A atividade foi desenvolvida pelos bolsistas do Programa de Educação Tutorial (PETCiências), da Universidade Federal da Fronteira Sul (UFFS), o qual propõe a formação interdisciplinar aos cursos de licenciatura em Química, Física e Ciências Biológicas, vinculando ensino, pesquisa e extensão, com ênfase em dois eixos principais: meio ambiente e formação de professores.

O programa está centrado na qualificação e (re)configuração dos espaços formativos, que compreende cursos da área das Ciências da Natureza ofertados pela universidade vigente. O PETCiências propõe o aprimoramento formativo, constituindo um perfil de professores pesquisadores, reflexivos e críticos. Ademais, direcionando licenciandos, professores, participantes e tutor a participar, interagir e qualificar as atividades integradas de ensino, pesquisa e extensão. Nesse âmbito, os bolsistas enxergam a necessidade de se integrar às escolas para levar novas propostas e abordagens de ensino que aproximem a universidade das escolas do município, desse modo, construindo um ambiente de formação dos professores da Educação Básica com os licenciandos.

Neste viés, licenciandos do curso de Ciências Biológicas juntamente com a professora da escola básica discutiram e analisaram temáticas a serem abordadas com a turma de discentes a qual a mesma leciona. A partir disso, foi elaborado um plano de aula sobre alimentação saudável, visto a importância de se trabalhar e (re)configurar concepções errôneas já constituídas no cotidiano da comunidade escolar. O objetivo dessa atividade era avaliar os conhecimentos prévios e subsequentes dos alunos a respeito do tema alimentação saudável, antes de ser introduzido o conteúdo pela professora da turma, e ainda capacitar os licenciandos quanto a sua capacidade de reflexão da prática pedagógica. 
O processo de formação deve dotar os professores de conhecimentos, habilidades e atitudes para desenvolver profissionais reflexivos ou investigativos. Nesta linha, o eixo fundamental do currículo de formação do professor é o desenvolvimento da capacidade de refletir sobre a própria prática docente, com o objetivo de aprender a interpretar, compreender e refletir sobre a realidade social e a docência (IMBERNÓN, 2011, p.41).

A proposta visa a discussão e interação dos alunos proporcionando um novo entendimento de alimentação saudável como forma de motivar a comunidade a mudar hábitos já enraizados, interferindo não apenas na saúde dos alunos, como também dos professores, funcionários, pais e responsáveis.

\footnotetext{
Adotar uma alimentação saudável não é meramente questão de escolha individual. Muitos fatores - de natureza física, econômica, política, cultural ou social podem influenciar positivamente ou negativamente no padrão da alimentação das pessoas (GOES, 2016, p.13-14) .
}

Nesse contexto, é nítido o acréscimo do consumo de alimentos industrializados tanto por influência dos grupos em que convivem como pela facilidade e praticidade que os mesmos oferecem. Dessa forma, a atividade pretende impulsionar os alunos a (re)pensar e mudar hábitos, discutir essas questões em suas casas e ambientes em que frequentam.

\begin{abstract}
Assim, visando a formação inicial de professores evidencia o papel relevante de um espaço formativo, em que licenciandos, professores da Escola e professores da Universidade dialogam, compartilham aprendizagens e gradativamente qualificam suas ações através da reflexão-análise constante de suas práticas, como sujeitos protagonistas do Ensino de Ciências (CALEGARO; HERMEL; GULLICH, 2013, p.3).
\end{abstract}

Conforme Accioly (2009, p. 1) "A comunidade científica já reconhece que os efeitos da alimentação inadequada em etapas precoces da vida podem acarretar consequências na saúde na vida adulta.”. A autora alerta ao fato de que o Brasil está passando por uma transição nutricional, a qual relaciona à má alimentação que resulta da falta de nutrientes essenciais ao corpo humano com o desenvolvimento de doenças que podem até levar ao óbito. Desse modo, é de suma importância que o professor trabalhe em sala de aula com essa temática, percebendo os riscos que os mesmos estão expostos. 
Dentre os riscos que a alimentação inadequada pode ocasionar, a abordagem acerca da obesidade vem sendo tratada na educação básica, isso porque grande parte dos alunos da rede pública realizam no mínimo uma refeição ao dia no ambiente escolar. Sendo assim, possibilitando que a reeducação alimentar seja introduzida no espaço e nas aulas de Ciências e Biologia, construindo conhecimento com os discentes em todos os processos de alcance que a nutrição possa se delimitar. Nas palavras de Lovato e Souza $(2016$, p. 5) “A Biologia pode contribuir no combate à obesidade através do estudo do processo de nutrição, desde a ingestão de alimentos, digestão, absorção, metabolismo e excreção.".

\section{METODOLOGIA}

O presente trabalho utiliza o método qualitativo (LÜDKE; ANDRÉ, 2013) em que "[...] analisar os dados qualitativos significa "trabalhar" todo o material obtido durante a pesquisa", levando-se em consideração desde a organização e a divisão até a identificação de padrões. Sendo assim, a análise do material disposto levou a uma observação geral seguida da análise dos elementos para a condução da pesquisa. O presente relato é resultado de uma ação formativa entre o PETCiências e uma escola da rede pública Estadual de Educação Fundamental, que resultou no planejamento e desenvolvimento de uma atividade prática para abordar sobre alimentação saudável com $8^{\circ}$ ano do Ensino Fundamental, na disciplina de Ciências. Participaram da atividade 16 alunos.

A iniciativa de realizar a atividade sobre o tema partiu da professora titular da turma, que ia iniciar o conteúdo com os seus discentes nas aulas de Ciências na qual o desenvolvimento da atividade foi proposta pelos bolsistas, como forma de diversificar a abordagem desta temática com os alunos. O objetivo central da aula prática era avaliar os conhecimentos prévios e subsequentes dos alunos a respeito do tema alimentação saudável, antes de ser introduzido o conteúdo pela professora da turma.

A turma foi dividida em grupos e cada grupo recebeu imagens aleatórias de alimentos (saudáveis e não saudáveis) sobre suas mesas (Fig. 1), então foi solicitado para 
que se possível cada aluno escolhesse imagens dos alimentos que contemplem suas dietas. Em grupo, os alunos foram desafiados a separar as imagens de alimentos selecionados em três sacolas identificadas (1- Alimentos saudáveis, 2- Alimentação alternativa, 3Alimentos não saudáveis) (Fig. 2), possibilitando a discussão em grupo.

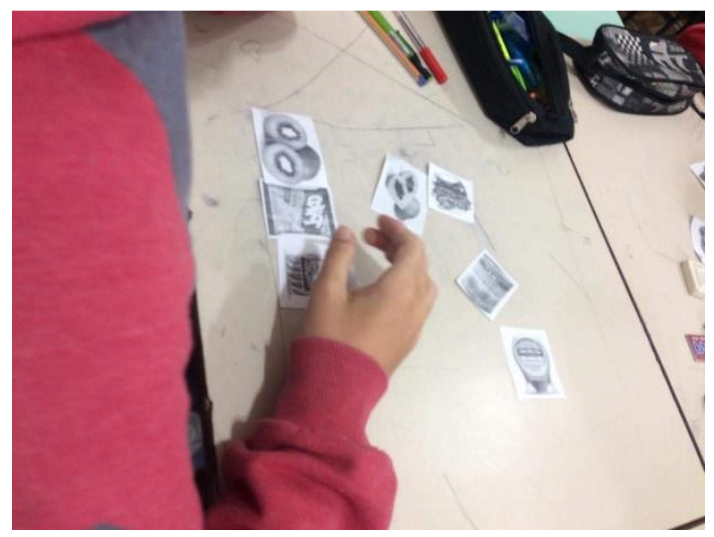

Figura 1 - Distribuição das imagens para os alunos

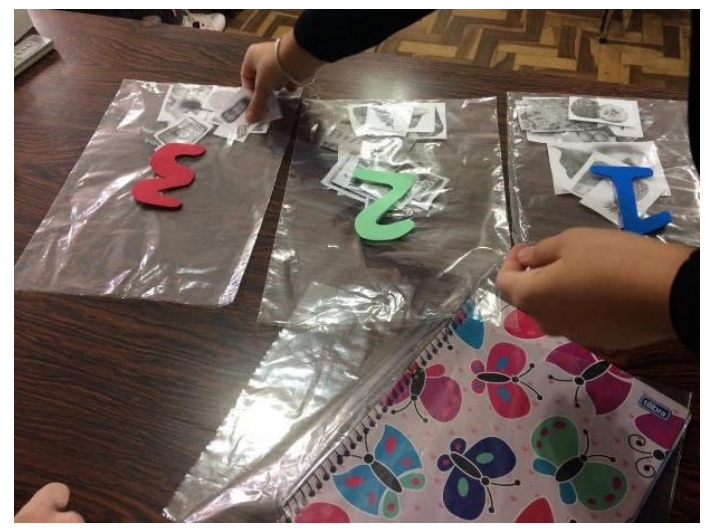

Figura 2 - Identificação das três sacolas (1- Alimentos saudáveis, 2- Alimentação alternativa, 3Alimentos não saudáveis)

Após a separação, conforme suas concepções sobre os alimentos, os licenciandos abordaram a importância e a composição de alguns alimentos encontrados nas sacolas, conferindo e verificando com os alunos se haviam alimentos trocados e possibilitando a (re)significação de conceitos construidos em conjunto com os alunos. Como forma de 
avaliação e registro da atividade foi elaborado um questionário, afim de evidenciar a aprendizagem dos discentes.

Questionário:

1- Cite alimentos que compõe sua dieta:

2- Coloque V se a informação for verdadeira e $\mathrm{F}$ se for falsa.

( ) Uma boa alimentação dá energia para o corpo funcionar bem.

( ) Tenho que comer muito para ter saúde.

( ) Só preciso comer se estiver com fome.

( ) A alimentação deve ser nutritiva, variada e em quantidade suficiente para ajudar no crescimento e desenvolvimento do organismo.

3- Após a prática realizada, você considera a sua alimentação diária saudável?

Para contextualizar, foi produzido um cartaz em grupo, expondo as sacolas com as imagens representativas de alimentos e sua separação correta. A ideia central era convidar a comunidade escolar a refletir sobre sua alimentação por meio da exposição do cartaz nas paredes da escola, problematizando "Em qual categoria sua dieta está realcionada?".

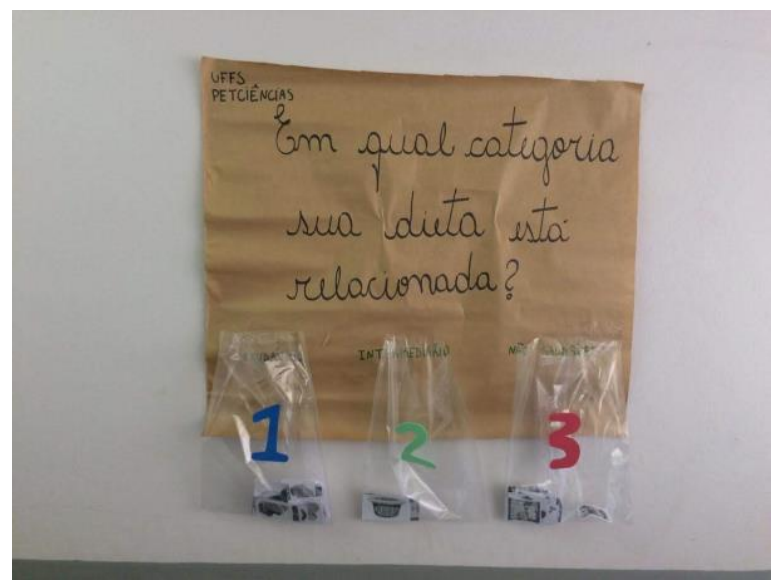

Imagem 3 - Exposição do cartaz nas paredes da escola

\section{RESULTADO E DISCUSSÃO}


Durante o desenvolvimento da atividade, buscamos contribuir para o entendimento dos alunos sobre o tema vigente, os quais se mantiveram atentos e participativos nos momentos de discussões e (re)formulações de conceitos já definidos por eles. O objetivo da prática era avaliar os conhecimentos prévios e subsequentes dos alunos a respeito do tema alimentação saudável, antes de ser introduzido pela professora da turma, onde participaram dessa ação 16 alunos do $8^{\circ}$ ano. A partir da avaliação das noções básicas dos discentes sobre alimentação saudável foi organizado um quadro (Quadro 1), que demonstra os carácteres expressivos de suas respostas ao questionário, fazendo um olhar a questão número três: Após a prática realizada, você considera a sua alimentação diária saudável?

Quadro 1: Resposta descritiva dos discentes referente a questão 3 do questionário.

\begin{tabular}{|c|c|c|}
\hline $\begin{array}{cc}\text { Considera } & \text { sua } \\
\text { alimentação saúdavel } & \end{array}$ & $\begin{array}{c}\text { Considera } \\
\text { alimentação intermediária }\end{array}$ & $\begin{array}{l}\text { Não considera sua } \\
\text { alimentação saudável }\end{array}$ \\
\hline "Sim" (Aluno 4) & $\begin{array}{l}\text { "Eu como alimentos } \\
\text { saudáveis, intermediários e não } \\
\text { saudáveis. Eu acho que sou } \\
\text { saudável, mas às vezes como } \\
\text { uma coisa não saudável” (Aluno } \\
\text { 1) }\end{array}$ & "Não" (Aluno 2) \\
\hline "Sim" (Aluno 5) & $\begin{array}{l}\text { "Mais ou menos, às } \\
\text { vezes como bastante besteiras", } \\
\text { (Aluno 7) }\end{array}$ & "Não" (Aluno 3) \\
\hline $\begin{array}{l}\text { "De certa forma sim, } \\
\text { pois poucos alimentos que } \\
\text { consumo não são saudáveis", } \\
\text { (Aluno 6) }\end{array}$ & $\begin{array}{l}\text { "Mais ou menos" } \\
(\text { Aluno 11) }\end{array}$ & $\begin{array}{l}\text { "Não, como algumas } \\
\text { coisas saudáveis, como frutas, mas } \\
\text { também como muitas coisas não } \\
\text { saudáveis" (Aluno 8) }\end{array}$ \\
\hline "Sim" (Aluno 14) & "As vezes" (Aluno 12) & $\begin{array}{l}\text { "Não, pois como algumas } \\
\text { saudáveis, mas na maioria das } \\
\text { vezes muitas coisas não } \\
\text { saudáveis" (Aluno 9) }\end{array}$ \\
\hline
\end{tabular}




\begin{tabular}{|c|c|c|c|}
\hline $\begin{array}{l}\text { "Sim, porque no meu } \\
\text { dia a dia eu como poucos } \\
\text { produtos industrializados" } \\
\text { (Aluno 15) }\end{array}$ & $\begin{array}{l}\text { "Mais ou } \\
\text { (Aluno 13) }\end{array}$ & menos" & $\begin{array}{l}\text { “Não, eu acho que devo } \\
\text { mudar minha alimentação, pois } \\
\text { como coisas que não são saudáveis } \\
\text { e agora eu sei que minha } \\
\text { alimentação está errada. E } \\
\text { também como coisas que são } \\
\text { saudáveis" (Aluno 10) }\end{array}$ \\
\hline & & & “Não" (Aluno 16) \\
\hline
\end{tabular}

O quadro se apresenta de forma muito equilibrada, visto que os alunos se dividiram em três movimentos: os que consideram sua alimentação saudável (5), os que acreditam ter uma alimentação intermediária (5) e, finalmente, os discentes que admitem que sua alimentação vem sendo desproporcional, ou seja, não saudável (6). Os alunos foram identificados por números de 1 a 16, para que seus nomes não fossem expostos. Analisando o primeiro elemento, foi possível perceber que 5 dos 16 alunos consideram suas rotinas alimentares bem conduzidas, demonstrando preocupação com sua saúde e mesmo conhecimento do que estão inserindo, quando destaca: "De certa forma sim, pois poucos alimentos que consumo não são saudáveis" (Aluno 6). Os alunos que apresentaram em suas respostas uma consciência positiva de sua alimentação gratificam a sala de aula por incentivar os demais alunos a aderir seus hábitos. Isso nas palavras de Goes (2016) mostra que a alimentação delibera de outros fatores para que seja constituída pelo indivíduo, ou seja, a influência de terceiros pode melhorar consideravelmente os hábitos do grupo.

A atividade tinha o intuito de fazer presente a reflexão dos alunos, isso porque a ação precisa atingir o nível de conscientização e, dessa forma, a construção do conhecimento abrangeria muito mais da capacidade crítica dos alunos.

As atividades experimentais devem ter sempre presente a ação e reflexão. Não basta envolver os alunos na realização dos experimentos, mas também procurar integrar o trabalho prático com a discussão, análise e interpretação de dados obtidos (ROSITO, 2008, p. 203).

A partir dos excertos retirados das respostas dos alunos é notória a presença da reflexão quando os alunos salientam: “Eu como alimentos saudáveis, intermediários e 
não saudáveis. Eu acho que sou saudável, mas às vezes como uma coisa não saudável” (Aluno 1), e ainda na passagem seguinte: “Não, eu acho que devo mudar minha alimentação, pois como coisas que não são saudáveis e agora eu sei que minha alimentação está errada. E também como coisas que são saudáveis" (Aluno 10). O aluno 1 demonstra seu entendimento sobre os diversos tipos de alimentos e alimentações, percebe que sua dieta demonstra ser satisfatória e mesmo equilibrada nutricionalmente, já o aluno 10 é mais enfático em suas palavras, pois percebeu após a atividade que sua alimentação não está muito adequada, mas reflete que é possível mudar e que sua perspectiva alimentar estava errada. Ambos os excertos demonstram mais claramente a (re)configuração de noções que os alunos observaram durante a atividade e como a mudança de conceitos será levada subsequentemente para suas vidas.

Em contraponto, os seis alunos que responderam massivamente que sua alimentação não era considerada adequada demonstram que estão cientes de suas atitudes, mas que mesmo sem largar alguns de seus maus costumes tentam reajustar sua dieta consumindo produtos orgânicos. Em suas palavras indicam: "Não, como algumas coisas saudáveis, como frutas, mas também como muitas coisas não saudáveis" (Aluno 8), e ainda, "Não, pois como algumas saudáveis, mas na maioria das vezes muitas coisas não saudáveis" (Aluno 9). Consideramos gratificante a contribuição dos alunos relatando sinceramente como se dá a sua dieta, mesmo que suas respostas ainda sejam negativas, acreditamos que a atividade possibilitou um (re)pensar em suas práticas e ainda oportunizou que novas opções de alimentos fossem introduzidas em seu cotidiano.

Nesse contexto é compreensível que a escola possa ser um espaço que ressalte a importância da alimentação saudável, tanto para os alunos que convivem no ambiente, como para a comunidade externa que de alguma forma se comunica com a instituição.

Apesar da idade destes alunos serem baixas (entre 9 e 10 anos), é ainda nessa fase que eles podem, junto aos seus familiares selecionar os alimentos a serem consumidos, bem como opinar sobre aqueles que trazem mais benefícios à sua saúde, influenciando de forma significativa na alimentação familiar. (TRAVAIN, S.; TRAVAIN, C.; ASSIS, A. , 2019, p. 14) 
Nas palavras de Goes (2016, p. 22) "“[...] quanto antes a criança for submetida a um costume de estilo de vida saudável, menor as chances de evolução para doenças crônicas não transmissíveis posteriormente". O autor evidencia que a escola possui um papel imprescindível na formação e constituição do indivíduo, desse modo, a preocupação da escola em trabalhar temas transversais como a saúde englobando a alimentação saudável, cumpre seu papel social.

\section{CONCLUSÃO}

A atividade realizada pelos bolsistas do programa PetCiências visava um (re)pensar das atitudes alimentares dos alunos, visto a necessidade que o tema possa agregar à comunidade escolar. Conscientizando os mesmos de como uma dieta adequada interfere na saúde e qualidade de vida. Com o desenvolvimento da atividade interativa, acredita-se que o uso de imagens representativas fazendo alusão aos alimentos que poderiam estar inclusos no consumo diário dos discentes fez com que a atividade se tornasse em um âmbito mais real.

O movimento de escolha das imagens para possível classificação (alimentos saudáveis, intermediários e não saudáveis) e discussão, abordando a composição e importância de cada alimento, foi o fator impulsivo para que ocorresse reflexão da prática cotidiana de cada discente. Com base na análise, identificou-se a presença reflexiva dos alunos quando denotam que deveriam mudar sua alimentação e, mesmo que a partir da atividade, foi possível perceber que muitos dos seus hábitos não eram adequados, demonstrando a conscientização presente em suas falas. Para socialização e retomada de alguns conceitos foi realizado um cartaz com a turma e exposto na parede da escola, o qual tinha como propósito a conscientização da comunidade escolar.

Ademais, faz-se indispensável que os professores em formação estejam constantemente refletindo e (re)pensando suas práticas pedagógicas, estando sempre conscientes das necessidades que a turma e mesmo a escola estão carecendo. E que, ainda, os programas de educação possam sempre contribuir para o engajamento e contato dos licenciandos com a Educação Básica, permitindo a interação e a inovação, na formação de indivíduos mais criativos. 


\section{REFERENCIAS}

ACCIOLY, E. A escola como promotora da alimentação saudável. Instituto de Nutrição Josué de Castro - UFRJ. Ciência em tela. v. 2, n. 2, 2009. Disponível em: http://www.mobilizadores.org.br/wp-content/uploads/2016/03/A-escola-comopromotora-da alimentacao-saudavel.pdf. Acesso em: 29 abr. 2019.

GOES. M. R. B. Avaliação da alimentação escolar oferecida aos alunos em creche. Natal/RN 2016. [TCC]. Disponível em: https://monografias.ufrn.br/jspui/bitstream/123456789/3285/1/Avalia\%C3\%A7\%C3\%A 3oalimenta\%C3\%A7\%C3\%A3oescolar 2016 Trabalho\%20de\%20Conclus\%C3\%A3o \%20de\%20Curso Acesso em: 29 abr. 2019.

IMBERNÓN, F. Formação docente e profissional: formar-se para a mudança e a incerteza. 9. ed. São Paulo: Cortez, 2011. 127 p.41

LOVATO, M. A. P.; SOUZA, J. M. T. Obesidade e qualidade de vida na escola. Caderno PDE, ISBN 978-85-8015-093-3 v. 1. Paraná. 2016. Disponível em: http://www.diaadiaeducacao.pr.gov.br/portals/cadernospde/pdebusca/producoes_pde/20 16/2016_artigo_bio_utfpr_mariaaparecidapereira.pdf Acesso em: 30 abr. 2019.

LÜDKE, Menga; ANDRÉ; Marli, E. D. A. Pesquisa em educação: abordagens qualitativas. 2. Ed. Rio de Janeiro. E.P.U. 2013.

ROSITO, B. A. O Ensino de Ciências e a Experimentação. In: MORAES, Roque (Org.). Construtivismo e Ensino de Ciências: Reflexões epistemológicas e metodológicas. Porto Alegre: EDIPUCRS, 2000.p.195-207.

TRAVAIN, S.; TRAVAIN, C.; ASSIS, A. A visão dos alunos do ensino fundamental sobre a caloria dos alimentos e seu impacto na saúde. Revista Insignare Scientia RIS, v. 1, n. 3, 17 fev. 2019.

CALLEGARO, K. ; HERMEL, E. E. S. ; GULLICH, R. I. C. ; ABDEL, J. E. D. Construindo um modelo de pirâmide alimentar: orientação para uma alimentação saudável. In: VI Encontro Regional Sul de Ensino de Biologia (EREBIO-SUL). XVI Semana Acadêmica de Ciências Biológicas., 2013, Santo Ângelo-RS. Anais do VI Encontro Regional Sul de Ensino de Biologia. XVI Semana Acadêmica de Ciências Biológicas: a docência em Biologia: da formação inicial à formação continuada tecendo CTSA., 2013. 